\title{
Projecting Future Population Dynamics of the Florida Snail Kite in Relation to Hydrology Using EVERKITE
}

EVERKITE is a spatially explicit, individual-based model designed as a management scenario evaluation tool for the endangered Florida snail kite (Rostrhamus sociabilis). Specifically, the model is designed to project how the movement, reproductive success, and mortality of snail kite populations respond to different scenarios of hydrologic change in the major wetlands of southern and central Florida. EVERKITE has been developed at the Netherlands Institute of Ecology, Centre for Limnology, under the U.S. Geological Survey (USGS) Across Trophic Level System Simulation (ATLSS) Program.

The Florida snail kite is an endangered raptor that occurs as a closed population of about 2,000 birds in the wetlands of southern and central Florida. The hydrology of these wetlands directly affects snail kite demography, and an individual-based model has been developed to project population change under proposed future hydrologic scenarios. A large number of empirical studies have been done on the Florida snail kite, providing basic information for the predictive model. These studies also provide the correlative relations between the hydrology of the system and specific aspects of snail kite life history and behavior. These relations form the building blocks of any hydrologically driven population dynamics model.

Two alternatives are available for modeling the life history of a population and involve either: (1) a system-wide deterministic matrix model, or (2) a spatially explicit, stochastic individual-based model. Rather than choosing between these two approaches, they were combined and implemented in a spatially explicit matrix model that can be run both in a deterministic and in a stochastic mode. This tool was used to address the challenge of making reliable projections of future population development of the snail kite under various hydrologic scenarios.

The reliability of the model can be determined by comparing model-predicted demographic patterns (using historical hydrologic data) with observed demographic patterns during recent decades. The annual count of snail kites that was performed during 1969-95 provides the type of data needed for such a comparison. This dataset has been criticized, however, for being biased in several ways. Without an unbiased dataset on kite numbers, it is not feasible to check the reliability of the kite model against the historical situation; this potentially limits the utility of the model in discriminating among hydrologic scenarios.

To circumvent this problem, we adopted the following research strategy. Rather than using a single version of the model, we implemented a suite of model versions representing the structural uncertainty in our understanding of the dynamics of the kite population. For each model version, we then developed a number of parameterizations, representing the uncertainty in the model parameters. We will evaluate each hydrologic scenario for each model version for each para-meterization, focusing on the longterm population growth rate $(\lambda)$ as the main response parameter. This analysis will enable us to evaluate whether structural uncertainty and parameter uncertainty interact with differences due to hydrologic scenarios. If these interactions are absent, they will prove to be a reliable tool for scenario evaluation, despite considerable structural and parameter uncertainty.

\section{How Does EVERKITE Work?}

The deterministic and stochastic versions of EVERKITE use the same basic mechanisms to simulate snail kite population dynamics in southern and central Florida. The model runs on a weekly time step, and each of the 15 major wetlands of southern and central Florida is represented. Additionally, there is a spatial unit called "peripheral habitat," which represents the small pockets of kite habitat scattered over southern and central Florida. These small pockets are assumed to form an important refuge for kites during system-wide droughts (Mooij and others, 2002), and therefore, to be an essential component of the model. The fate of each kite for each week is evaluated using the following schedule (fig 1). First, each kite is checked to determine whether it makes the transition to a new life stage

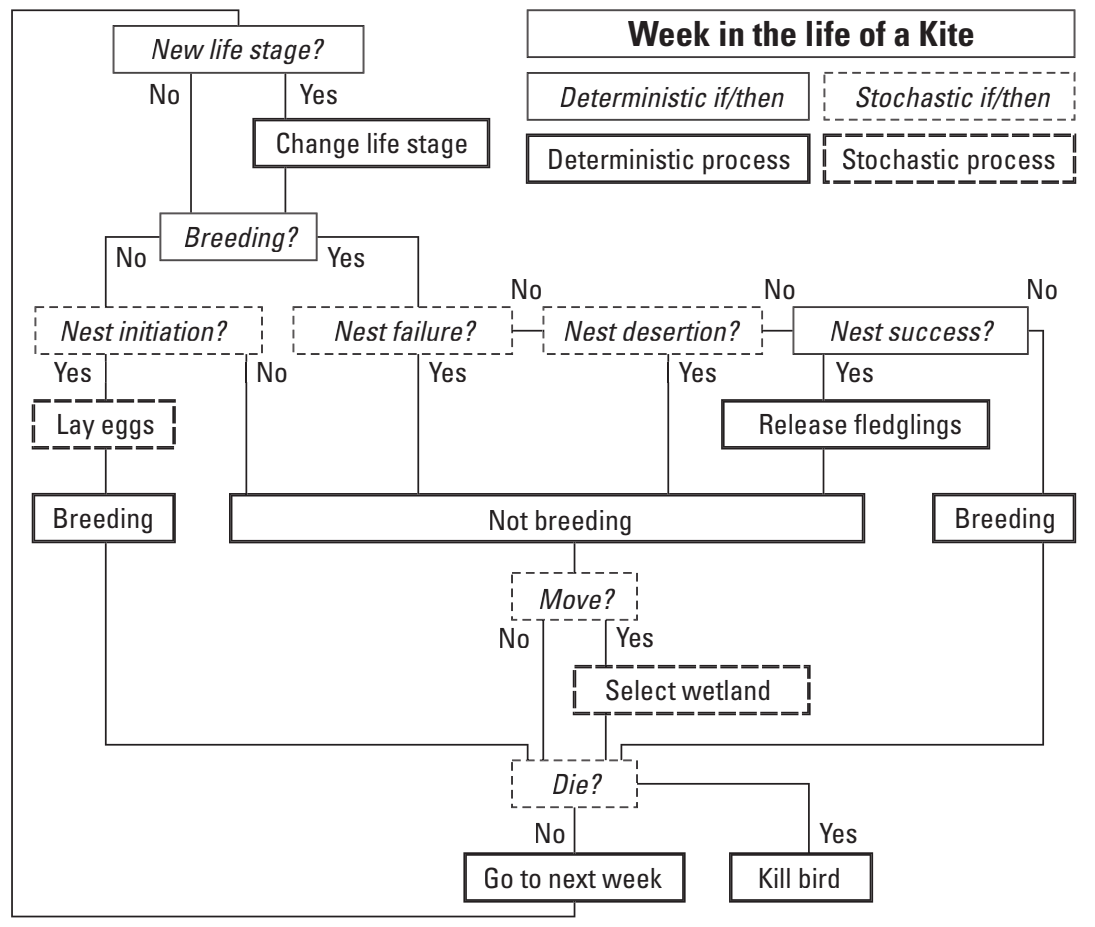

Figure 1. Flow chart of the logic applied in EVERKITE to each kite for each week. 
during a given week. Second, the current breeding status is checked, and a new breeding status is assigned if necessary. The probability of a change in breeding status is determined by the hydrologic conditions in the wetland where the kite is located. Third, nonbreeding birds are given the opportunity to move to another wetland. The probability of movement and probability of choosing a given wetland are both determined by the hydrologic conditions. Finally, each kite has a probability of dying in a given week, depending on its life stage and the hydrologic conditions.

\section{How Is EVERKITE Implemented?}

EVERKITE simulations have been implemented in $\mathrm{C}++$ as an application of the OSIRIS modeling framework. An interface to input the model with the relevant parameters, initial conditions, and hydrologic data has been developed both in Microsoft EXCEL and ACCESS (fig. 2). Numerical output produced by the model can be retrieved using the same interface. Graphical output has to be created by the end users from the numerical output, using the graphical capacities of EXCEL, ACCESS, or any other program of choice.

\section{What Output Does EVERKITE Produce?}

EVERKITE produces a number of kites in each wetland for each week over the duration of the hydrologic scenario. A good way to characterize a given scenario in a single number is to calculate the long-term population growth rate $(\lambda)$ for the whole period covered by the scenario. An additional advantage of using the long-term population growth rate rather than absolute numbers is that the latter depends on an estimate of the initial population size, which is likely to be fairly unreliable.

For scientific use, further breakdown of the number by life stage, breeding status, and wetland is possible both in the stochastic and the deterministic version of the model. EVERKITE has been run for each of the scenarios that were considered during the Restudy, and its output has been provided to the agencies involved. It also will be used to evaluate new Comprehensive Everglades Restoration Plan (CERP) scenarios.

\section{Reference}

Mooij, W.M., Bennett, R.E., Kitchens, W.M., and DeAngelis, D.L., 2002, Exploring the effect of drought extent and interval on the Florida Snail Kite: Interplay between spatial and temporal scales: Ecological Modelling, v. 149, p. 25-39.

\section{For more information contact:}

Wolf M. Mooij
Netherlands Institute
of Ecology
Centre for Limnology
Rijksstraatweg 6
3631 AC Nieuwersluis
The Netherlands
w.mooig@nioo.knaw.nl

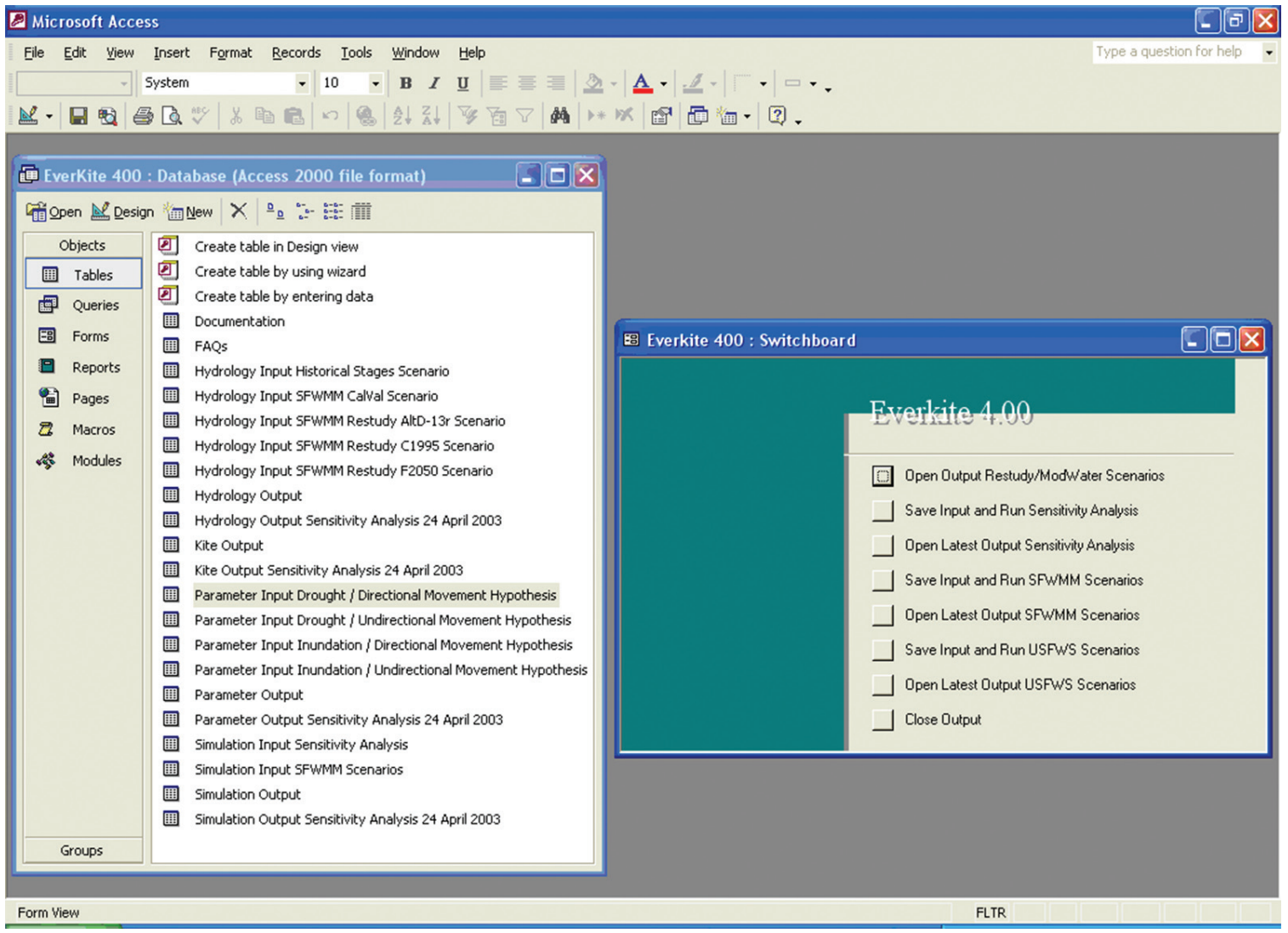

Figure 2. Main screen of the Microsoft Access interface to EVERKITE. 